Submission ID: 43869

\title{
Studying of Wave Processes in a Rock Mass by Technique for Recognizing
} Fractured Zones in Fields of Seismic Waves

\author{
I.I. Semerikova* ( Mining Institute of the Ural Branch of Russian Academy of Sciences, Perm \\ National Research Polytechnic University)
}

\section{SUMMARY}

The results of the application of the specialized interpretation technique for recognizing fractured zones in areas of fractured reservoirs in Eastern Siberia are presented. The technique is based on the search criteria we established in the amplitude and spectral parameters of longitudinal reflected waves, developed at the Mining Institute of the Ural Branch of the Russian Academy of Sciences. Prospecting indicators for fractured geo-objects of different types are established a posteriori by examining the links between fractures' parameters and dynamic attributes both in the laboratory as well as under conditions of natural occurrence of rocks. he search for a physical justification for the established patterns of behavior of the dynamic parameters of seismic waves allows us to study and understand more deeply the wave processes occurring in an array of fractured rocks. The effect of increasing the value of the frequency coordinate of the centroid in the zones of small differently oriented cracks is revealed, which manifests itself both in mathematical and physical modeling, and on fractured objects of oil and ore deposits. It can be realized due to non-coherent summation of waves of different frequency and amplitude. The presence of different-frequency waves, in our opinion, is due to the internal structure of the fracturing zone, in which the formation of waves of different types: separate interference waves, multiply reflected from the superface and the subface inside the fracture; channel-wave signal - Rayleigh wave modes and Love wave modes; monochromatic waves on which an incident wave splits in when reflected of non-mirror from geometrically and physically rough interfaces; diffracted waves. 
Изучение волновых процессов в массиве горных пород по методике распознавания трещиноватых сред в полях сейсмических волн.

Семерикова И. И.* (Горный институт УрО РАН, Пермский национальный исследовательский политехнический университет)

\section{Введение}

Для исследования трещиноватости, отождествляемой как безамплитудные или малоамплитудные нарушения сплошности пород с различным аспектным отношением, на сегодняшний день существует лишь некоторый ряд специализированных технологий. Принципы и физические основы, результаты методического и опытно-производственного опробования представлены в ряде работ и докладов на международных конференциях и симпозиумах. Большая работа по представлению характеристик опробированности и режимов применения методов и технологий проведена группой российских ученых Левянт и др. (2010). Анализ эффективности данных методов показал, что подавляющее большинство из них относятся к классу косвенных и обратная задача решается ими весьма неопределенно, т. е. природа эффектов, на использовании которых основываются данные методы, например, рассеянные волны, многофакторна. Трещиноватость - далеко не единственный фактор, обуславливающий эти эффекты, из чего следует, что решение обратной задачи неоднозначно. Последнее обстоятельство вызывает существенное разочарование в результатах применения этих методов. Последнее время появились работы, в которых ищутся прямые отклики от трещин и их скоплений при сейсмической разведке. Это связано с исследованием возможностей использования прямых откликов от трещин для картирования зон их распространения, а также обеспечения базовой информацией разработки методов обнаружения этих зон. Однако чаще всего приводятся результаты лишь методов решения прямой задачи математического сейсмомоделирования волновых полей. Численные методы, используемые при этом, интенсивно развиваются (Квасов и др., 2016): лучевой метод, метод акустического приближения, метод осредненных моделей, метод конечных элементов, спектральные и псевдоспектральные методы, конечно-разностные методы, разрывный метод Галеркина, сеточно-характеристические методы. В тоже время, эта тенденция обусловлена пониманием того, что метод сейсмомоделирования имеет существенные ограничения, так как его результаты в крайней степени зависят от адекватности задания модели трещиноватости. Кроме того, исследуются в основном амплитудные характеристики.

Методика. Наши исследования, целью которых является создание специализированной интерпретационной методики прямого распознавания трещиноватых сред (Семерикова, 2005, Семерикова и др., 2012), не ограничились изучением лишь амплитудных характеристик упругих волн, а также выявлялись закономерности изменчивости характеристик в частотной области. При этом решались следующие, относящиеся к классу фундаментальных, задачи: 1) задача выявления и установления поисковых признаков трещиноватых геообъектов в амплитудных и спектральных параметрах отраженных продольных волн; 2) установление их устойчивости, статистической значимости, выявление закономерностей их изменчивости в зависимости от изменчивости характеристик трещин; 3) построение алгоритма конструирования эффективного параметра, характеризующего вероятность наличия трещиноватого объекта того или иного класса. Для выявления совокупности идентификационных поисковых признаков использовались независимые методы: имитационное математическое моделирование синтетических волновых полей для множества моделей, содержащих трещины различных типов; физическое моделирование системы наблюдений 2-D сейсморазведки на больших образцах натуральных горных пород; моделирование системы наблюдения в постановке 3D на искусственной физической модели; метод «обучающих» объектов с известной трещиноватостью в условиях естественного залегания пород. Различия признаков позволяют производить распознавание зон, различающихся внутренней структурой: зоны одиночных протяженных трещин (линейные размеры больше длины волны), и зоны мелких разноориентированных трещин. Как показал опыт применения методики на объектах Верхнекамского месторождения калийных солей, 
Юрубчено-Тохомской зоны (Семерикова, 2012, 2015, 2016), появилась

возможности выделения трещиноватых слоев мощностью в первые метры.

Изучение волновых процессов. Результаты позволяют использовать данные признаки для решения различного класса прикладных и научных задач. В частности, поиски физического обоснования выявляемых закономерностей поведения динамических параметров сейсмических волн необходимы в качестве «ключа» для понимания «механизма» волновых процессов, происходящих в массиве горных пород. Например, эффект увеличения значения частотной координаты центроида в зонах мелких разноориентированных трещин, проявляющийся как при математическом и физическом моделированиях, так и во всех экспериментах на трещиноватых объектах нефтяных и рудных месторождений, мы связали с несинфазным суммированием волн с различной частотой и амплитудой. Присутствие же разнообразных волн, на наш взгляд, обусловлено внутренней структурой зоны трещиноватости. Например, если трещину аппроксимировать тонким слоем (мощность слоя в два и более раз меньше расстояния между передним и задним фронтами волны), заполненным флюидом, и, следовательно, обладающим самым наименьшим волновым сопротивлением в массиве горных пород, то спектр сложной отраженной волны (Гурвич и Боганик, 1980), состоящей из отдельных наложенных волн, отразившихся кратно от кровли и подошвы внутри слоя, обогащается высокочастотными составляющими. Кроме того, поверхность такой трещины можно аппроксимировать свободной поверхностью, а саму трещину - внутренним волноводом. Тогда в таком контрастном слое возникают каналовые волны (Гурвич и Боганик, 1980): моды волны Рэлея и моды волны Лява. Все каналовые волны обладают дисперсией фазовой скорости. Во всех случаях дисперсия скорости приводит к растяжению первоначальной импульсной волны в пространстве и, соответственно, к удлинению графика колебаний. При нормальной дисперсии вблизи переднего фронта волны концентрируются длинноволновые составляющие, и график колебаний характеризуется убыванием видимых периодов со временем, при аномальной дисперсии видимые периоды возрастают.

Кроме того, внутренняя структура зон мелких разноориентированных трещин может образовывать геометрически и физически шероховатые границы, для которых лучи отраженной волны могут быть расходящимися или сходящимися. В результате сложной интерференции волн помимо зеркально-отраженной волны возникают также незеркальноотраженные волны (Гурвич и Боганик, 1980). При незеркальном отражении происходит расщепление первоначальной импульсной волны на различные монохроматические составляющие, отражаемые под различными углами. Частотный состав отдельных побочных волн отличается от частотного состава падающей волны. Кроме того, элементы внутренней структуры таких зон трещиноватости могут явиться дифрактороми - препятствиями, имеющими малую по сравнению с длиной волны область среды с существенно различными упругими свойствами, порождающие дифрагированные волны. Их кинематические и динамические особенности зависят от формы и размеров, степени и характера различия упругих свойств и вида падающей волны (Гурвич и Боганик, 1980). Видимый период дифрагированной волны больше падающей. Спектр дифрагированной волны отличается от спектра падающей дополнительным множителем, обратно пропорциональным корню из частоты. Таким образом, эффект увеличения частотной координаты центроида может реализовываться за счет несинфазного суммирования волн разной частоты и амплитуды.

Пример. Таимбинский участок примыкает с запада к Куюмбинскому и Юрубчено-Тохомскому участкам. Гигантское скопление углеводородов этих двух крупнейших месторождений обнаружено в 70-х гг. в древнейшем рифейском карбонатном каверново-трещинном резервуаре. Согласно концепции академиков А.Э. Конторовича, А.А. Трофимука, и других исследователей эти месторождения образуют ядро КЮТа, в состав которого входят так же перспективные нефтегазогеологические объекты соседних площадей. Однако, в четырех скважинах, пробуренных на Таимбинском участке, вскрывших рифей, результаты оказались отрицательными. В связи с этим пришлось разрабатывать принципиально новые модели трещинного рифейского резервуара. Рифейский комплекс характеризуется широким развитием зон интенсивной дислокации рифейских отложений, перекрытых несогласно субгоризонтально залегающими вендскими образованиями. Большие углы падения обуславливают то, что на размытую поверхность рифея выходят разные по возрасту и литологическому составу толщи. 
Расчленение рифейских отложений является самой сложной из стратиграфических проблем Сибирской платформы. На рис.1 а представлен традиционный временной разрез. Целевыми

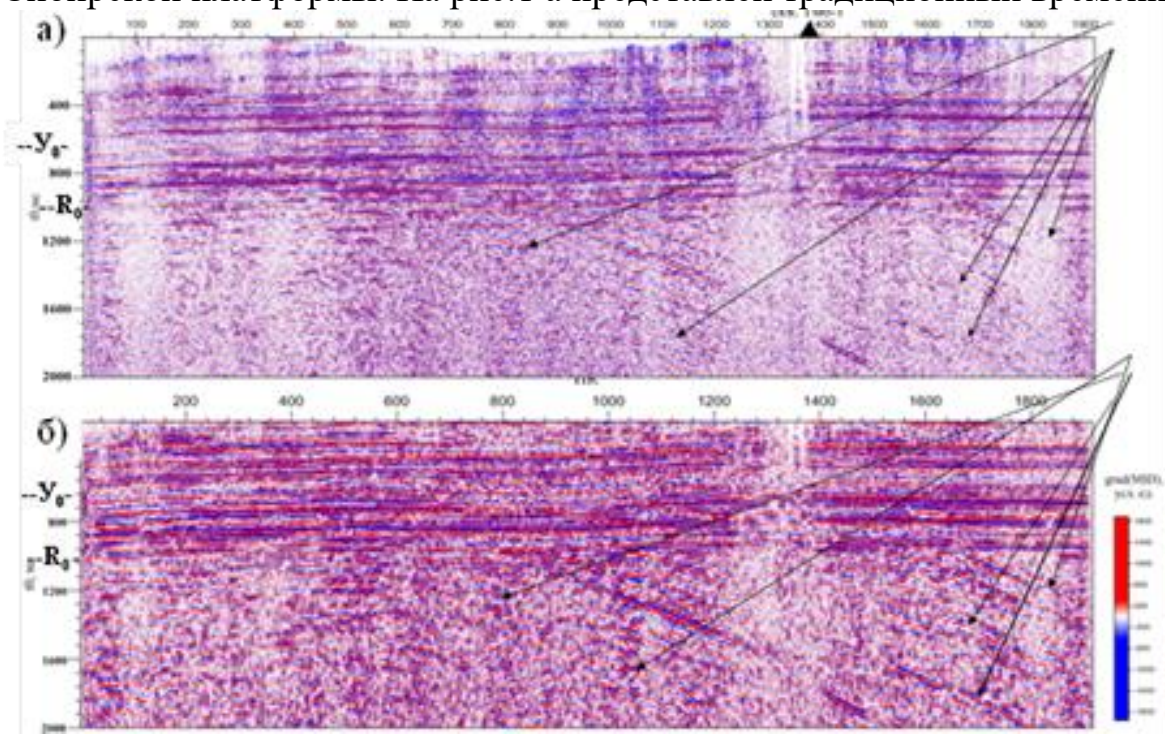

Рисунок 1. Сопоставление временного разреза (ОАО «Енисейгеофизика») а) и разреза градиента средних амплитуд

интервалами являются толщи пород, залегающими в области несогласия и выше: между отражающими горизонтами $\mathrm{y}_{0}$ - внутри усольской свиты, и $\mathrm{R}_{0}$ - эрозионная поверхность кровли рифея. Резкая смена волновой картины, выражающаяся в угловом несогласии отражающих горизонтов в толще рифея с вышележащими отложениями, присутствует в области субгоризонтального отражающего горизонта $\mathrm{R}_{0}$. Однако, изменчивость волновой картины и в целевом интервале, и вне его, не отличается характерными особенностями картин в других вышележащих интервалах. Определение природы этих особенностей волновой картины, представляют существенную трудность. Проблема на данной территории - весьма затруднительная корреляция внутририфейских круто наклонных горизонтов. Оказалось, выраженность крутопадающих осей синфазности отражающих горизонтов в рифейской толще более уверенна на разрезах ряда амплитудных характеристик сейсмозаписи, входящих в необходимый набор поисковых признаков нашей методики: средние амплитуды, градиенты средних амплитуд (рис. 1 б), чем на временном разрезе, где не удается их прокоррелировать в силу их слабой интенсивности (Семерикова, 2015). На разрезах эффективного параметра, оценивающего вероятность наличия зон протяженных трещин, его повышенные значения проявляются в нижних структурных этажах, соответствующих, по-видимому, фундаменту. Здесь особое внимание геологи обратили на то, что субгоризонтальная поверхность, на которой затухают протяженные трещины, неконформна наклонным отражающим границам выделяемых рифейских отложений. Повышенные значения эффективного параметра, характеризующего вероятность наличия мелкой разноориентированной трещиноватости, следует идентифицировать с зонами с улучшенными коллекторскими свойствами. Пример его пространственного распределение представлен на рис. 2. Наиболее значимые зоны трещиноватости выделены пунктиром. На разрезах этого параметра в различных интервалах трещиноватость распределена неравномерно: и весьма локально, и формирует довольно обширные зоны, а также трещиноватость, развитую по отдельным пластам. Особое внимание прежде всего к зонам в нефтегазоперспективной области отражающего горизонта $\mathrm{R}_{0}$, т.е. зонам выхода карбонатных отложений рифейского комплекса пород на эродированную предвендскую поверхность. В этих зонах геологами предполагается, что «в результате длительного предвендского перерыва в сочетании с тектоническими перестройками, следует ожидать развитие коллекторов трещинного и каверно-трещинного типа». «В процессе миграции углеводороды заполняли ловушки как в головах рифейских толщ ниже поверхности несогласия, так и в пластах песчаников варнаварской свиты венда выше поверхности несогласия...» («неопубл. результаты» Канторович А.А., 2014). 


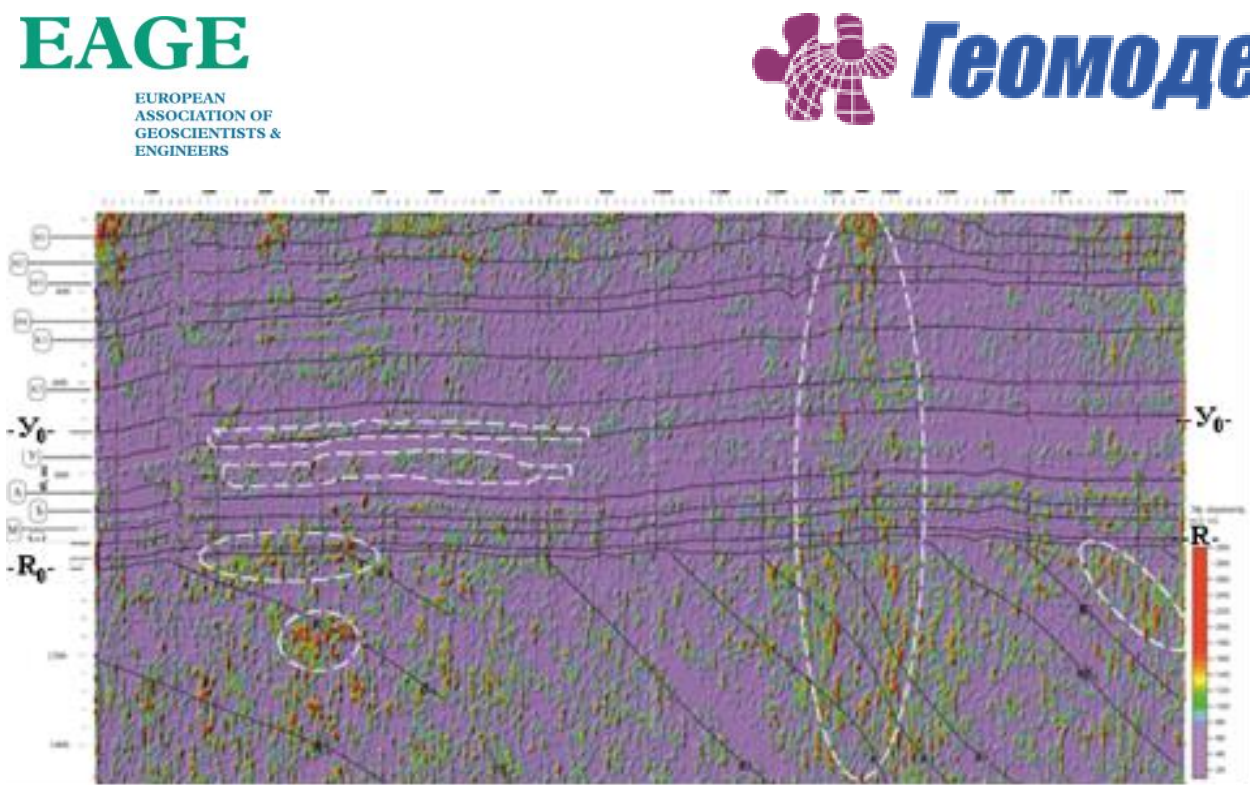

Рисунок 2. Разрез эффективного параметра, характеризующего вероятность наличия зон мелких трещин (привязка отражающих горизонтов по ОА «Ениисейгеофизика»)

\section{Выводы}

Установленные признаки напрямую прогнозируют наличие трещиноватости независимо от ее генезиса и литологического типа пород. Это позволило снизить неоднозначность решения обратной задачи сейсморазведки. Поиски физического обоснования для установленных закономерностей поведения динамических параметров сейсмических волн позволяют глубже понимать волновые процессы, происходящие в массиве трещиноватых горных пород.

\section{Благодарности.}

Автор приносит благодарность заместителю начальника ИТЦ по работам в ВосточноСибирском регионе ООО «Газпром геологоразведка» Конторовичу А. А. за интерес, проявленный к нашим работам, и предоставленную возможность использования априорной информации. А также заведующему лабораторией Многоволновой сейсморазведки ГФУП «ВНИИгеофизика», Кузнецову В. М. за частные беседы и дискуссии, зародившие новые идеи.

\section{Библиография}

Гурвич И. И., Боганик Г.Н. [1980] Сейсмическая разведка: Учебник для вузов. М.:Недра, 551 с. Квасов И. Е., Левянт В. Б., Петров И. Б. [2016] Решение прямых задач сейсморазведки в трещиноватых средах методом характеристического моделирования. - M.: OOO «ЕАГЕГеомодель», 296 с.- ISBN 978-94-6282-181-1

Левянт В.Б., Хромова И. Ю., Козлов Е.А., Керусов И. Н., Кащеев Д. Е., В. В. Колесов В. В., Мармалевский Н. Я. [2010] Методические рекомендации по использованию данных сейсморазведки для подсчета запасов углеводородов в условиях карбонатных пород с пористостью трещинно-кавернового типа. Под редакцией В.Б. Левянта.- Москва, ЦГЭ, 250 с. Семерикова И. И. [2005] Методика распознавания трещинных сред в сейсмических волновых полях. 7 Международная научно-практическая конференция «Геомодель - 2005», С. 97 Семерикова И. И. [2015] Методика распознавания трещиноватых сред в полях отраженных волн для прогноза коллекторов углеводородов. /Экспозиция Нефть Газ. Научно-технический журнал, N6(45), С. 44-48. ISSN 2076-6785

Semerikova I. I. [2012] Technique for Recognizing of Fractured Zones Based on the Analysis of Amplitude and Frequency Attributes of the P-P Reflections. 74th EAGE Conference \& Exhibition incorporating SPE EUROPEC 2012, Copenhagen, Denmark, номер W044

Irina I Semerikova, J Russ Evans, David C Booth, Hengchang Dai and Tatiana S Blinova. [2012] A new technique for recognizing fractured zones in P-P reflection fields, applied to the study of a North Sea oil reservoir. Russian Journal of Earth Sciences. Vol 12, ES5002, No 5. Ресурс сети Интернет doi: 10.2205/2012ES000523

Semerikova I. [2016] Studying of Factured Reservoir by Technique for Recognizing Fractured Zones in Fields of Seismic Waves. Geomodel 2016 - 18th Science and Applied Research Conference on Oil and Gas Geological Exploration and Development. DOI: 10.3997/2214-4609.201602260 


\section{References}

Gurvich I. I., Boganik G.N. [1980]. Seismic prospecting: Textbook for high schools. M .:Nedra, 551 p.

Kvasov I. Ye., Levyant V. B., Petrov I. B. [2016]. Resheniye pryamykh zadach seysmorazvedki v treshchinovatykh sredakh metodom kharakteristicheskogo modelirovaniya. - $M$.: OOO «YEAGEGeomodel'», 296 p.- ISBN 978-94-6282-181-1

Levyant V.B., Khromova I. YU., Kozlov Ye.A., Kerusov I. N., Kashcheyev D. Ye., V. V. Kolesov V. V., Marmalevskiy N. YA. [2010] Metodicheskiye rekomendatsii po ispol'zovaniyu dannykh seysmorazvedki dlya podscheta zapasov uglevodorodov v usloviyakh karbonatnykh porod s poristost'yu treshchinno-kavernovogo tipa. Pod redaktsiyey V.B. Levyanta.- Moskva, CGE, $250 \mathrm{p}$. Semerikova I. I. [2005]. Metodika raspoznavaniya treshchinnykh srednikh v seysmicheskikh volnovykh polyakh. Geomodel 2005 - 7th Science and Applied Research Conference on Oil and Gas Geological Exploration and Development, pp. 97-99.

Semerikova I. I. [2015]. Recognizing technique of fractured media in p-p reflection fields for reservoir forecast hydrocarbons accumulation / Exposition Oil \& Gas. Scientific and technical journal, N6 (45), pp. 44-48. ISSN 2076-6785

Semerikova I. I. [2012] Technique for Recognizing of Fractured Zones Based on the Analysis of Amplitude and Frequency Attributes of the P-P Reflections. 74th EAGE Conference \& Exhibition incorporating SPE EUROPEC 2012, Copenhagen, Denmark, number W044

Irina I Semerikova, J Russ Evans, David C Booth, Hengchang Dai and Tatiana S Blinova. [2012] A new technique for recognizing fractured zones in P-P reflection fields, applied to the study of a North Sea oil reservoir. Russian Journal of Earth Sciences. Vol 12, ES5002, No 5. Internet resource doi: 10.2205/2012ES000523

Semerikova I. [2016] Studying of Factured Reservoir by Technique for Recognizing Fractured Zones in Fields of Seismic Waves. Geomodel 2016 - 18th Science and Applied Research Conference on Oil and Gas Geological Exploration and Development. DOI: 10.3997/2214-4609.201602260 